\title{
Comparison of Aptitude Test Scores of The Students Who Win and Who Cannot Win Sports High School
}

\author{
Fatma Çelik Kayapınar ${ }^{1}$, İlknur Özdemir ${ }^{2}$, Kamil Dikici ${ }^{3}$
}

\begin{abstract}
${ }^{1}$ Mehmet Akif Ersoy University, fatmailayda@gmail.com
${ }^{2}$ Pamukkale University, nurozdemir@pau.edu.tr

${ }^{3}$ Çukurova University, kdikici@cu.edu.tr
\end{abstract}

Received: 02.12.2017

Accepted: 12.01.2018

Online Published: 08.03.2018

doi: $10.30655 /$ besad.2018.2

\begin{abstract}
The purpose of the study was comparing the differences between the scores of the students who passed and who could not pass Aptitude Tests for sports high schools. The study was conducted with 101 students (male: $n=67$; female: $n=34$ ) who took and succeeded the Aptitude Test in 2017-2018 academic year among 206 students (male: 152; female: 54), and with 105 students (male: $n=85$; female: $n=20$ ) students who could not pass the test. The students participated in the coordination track, 30-m speed, standing long jump, rhythm tests, and received scores according to their performances. The Sports Player Background Scores (if any) were added to their scores and the Sportive Success Scores (SSS) were determined. The Sports Player Background Scores (if any) were added to their scores and the Sportive Success Scores (SSS) were determined. Mann-Whitney U test was used in comparisons to identify the difference between academic success and ability test points of male and female participants who passed or failed the test, and Kruskal Wallis $H$ test was used to identify the difference among the groups. At the end of the study, the difference in sports ability test points of the female and male participants who passed the test and the ones who failed the test were statistically significant. Male and female participants in third category had the highest point in sports ability tests and school placement.
\end{abstract}

Keyword: Aptitude test, sports high school, academic success

\section{Spor Lisesini Kazanan ve Kazanamayan Öğrencilerin Yetenek Test Puanlarının Karşılaştırılması}

\section{Öz}

Çalışmanın amacı 2017-2018 öğretim yılında spor lisesi yetenek sinavina girerek başarılı olup kayıt yaptırma hakki kazanan ve başarısız olup elenen ögrencilerin yetenek testlerindeki başarı puan farklılıklarını karşılaştırmaktır. Çalışma 2017-2018 öğretim yılında spor lisesi yetenek sınavına giren 206 (erkek:152; kadın:54) kişi arasından sinavı kazanan n=101 (erkek:67 kadın:34) ve kazanamayan $n=105$ ( $n=85$ erkek; $n=20$ kadın) aday ile gerçekleştirilmiştir. Yetenek sinavına giren öğrenciler; koordinasyon parkuru, $30 \mathrm{~m}$ sürat, durarak uzun atlama, ritim testlerine katılarak derecelerine göre puan almışlardır. Bu testler tamamlandıktan sonra aldıkları puanlara ek olarak varsa sportif özgeçmiş puanları eklenmiş ve Sportif Başarı Puanları (SBP) belirlenmiştir. Sinavı kazanan ve kazanamayan kadın ve erkek adayların akademik başarıları ve yetenek test puanları arasındaki farklılı̆̆ belirlemek için ikili karşılaş̧ırmalarda Mann-Whitney U testi, gruplar arasındaki farklılı̆̆ı belirlemek için Kruskal Wallis $H$ testi kullanılmıştır. Çalışma sonucunda; sınavı kazanan erkek ve kadın adayların kazanamayanlara göre sportif yetenek test puanları arasındaki fark istatistiksel olarak anlamlidır. Üçüncü kategoride yer alan erkek ve kadın adaylar okula yerleştirme ve sportif başarı testlerinde en yüksek puanları almışlardır.

Anahtar kelime: Yetenek sınavı, spor lisesi, akademik başarı 


\section{Giriş}

Spor Liseleri Anadolu Lisesi statüsünde olup güzel sanatlar ve spor eğitimi alanında yatıll, gündüzlü ve karma olarak ortaokul üzerine 4 yıl eğitim ve öğretim yapılan okullardır. Bu okullar, öncelikle güzel sanatlar ve sporla ilgili yükseköğretim kurumlarının bulunduğu yerlerde açılır. Spor Liseleri’nin amacı öğrencilerin ilgi, istek ve yetenekleri doğrultusunda spor eğitimi ile ilgili temel bilgi ve beceriler kazanmalarına yönelik eğitim-öğretim görmelerini ve alanlarında başarılı bireyler olarak yetişmelerini, yükseköğretim programlarına hazırlanmalarını, Türk sporuna katkıda bulunan ve başarıyla temsil eden bireyler olarak yetişmelerini, iş birliği içinde çalışma ve dayanışma alışkanlığı kazanarak takım ruhu ile hareket etmelerini, alanlarıyla ilgili araştırma yaparak yorum ve uygulama yetkinliğine ulaşabilmelerini, millî ve milletlerarası sportif faaliyetleri takip ederek bilgi ve kültürlerini geliştirmelerini, spor disiplini ve centilmenliğini benimseyen bireyler olarak yetişmelerini sağlamaktır (Milli Eğitim Bakanlığı, 2009).

Spor liseleri diğer liselerden farklı olarak öğrencilerini yetenek sınavı ile almaktadır (Milli Eğitim Bakanlı̆̆ı, 2009). Yetenekli öğrencilerin seçimi planlı ve sistematik bir çalışma ile gerçekleştirilir. Bu öğrenciler motor becerileri, genel fiziki yeterlilik ve fiziki gelişim gibi alanlarda çeşitli testlere tabi tutularak seçilirler (Çelik, Günay, \& Aksu, 2013). Benzer şekilde Türkiye'de olduğu gibi Almanya modeli ve İsveç modeli (TTA) gibi yetenekli çocukların özel olarak belirlendiği dünya sistemleride vardır (Muratl1, 2007). Türkiye'de bu seçmeler Milli Eğitim Bakanlığı tarafından orta öğretim kurumlar yönetmeliğine uygun şekilde tasarlanır. Yetenek sınavında 50 (elli) baraj puanının altında kalan öğrenciler başarısız sayılırlar ve değerlendirmeye alınmazlar. Yetenek sınavında 50 ve üzerinde puan alanların, yetenek sınavının \% 70’i ile 100'lük sisteme dönüştürülen ortaöğretime yerleştirme başarı puanının \%30’u alınarak 100 (yüz) tam puan üzerinden, puan üstünlüğüne göre değerlendirme yapılarak sıralanır (Milli Eğitim Bakanlığı, 2009). Spor liseleri yetenek sınavlarında uygulayacakları testleri Milli Eğitim Bakanlığı'nın belirtmiş olduğu testler arasından saha ve tesis olanaklarına göre belirleyerek ilan ederler. Ayrıca spor liselerine alınacak öğrenciler ile ilgili kontenjan sınırlaması vardır. Her yıl alınacak öğrenci ve oluşturulacak şube sayısı, okulun fizikî imkân ve donanımı dikkate alınarak komisyon tarafından belirlenir ve bir şubeye alınacak öğrenci sayısı 30'dur ve 9 uncu sınıfa her yıl alınacak öğrenci sayısı 5 şubeyi geçemez (Milli Eğitim Bakanlığı Ortaöğretim Kurumları Yönetmeliği, 2016).

Spor liselerine yerleşmek isteyen öğrenciler yetenekleri doğrultusunda sınav parkurlarında birbirleriyle mücadele etmektedir. Yetenek kavramı son zamanlarda özellikle psikoloji, 
pedagoji ve sosyoloji gibi bilim dalları tarafından sıkça ele alınan ve tartışılan bir kavramdır. Hareketsel yeteneğin oluşmasının şartları statik yetenek kavramı ve dinamik yetenek kavramı ile açıklanmaktadır.

Bireyin doğumundan itibaren genetik şema bellidir ve hastalık, beslenme yetersizliği olmadığı takdirde erişeceği boy ve fizik tipi, fibril tipi, fibril düzeni ve zekâsı da kalıtsal şema ile aktarılır. Bütün bu özellikler potansiyel yetenek kavramını oluşturur ve statik yetenek sportif başarının büyük ölçüde kalıtımla belirlendiğini, gelişmesinin ise salgı bezlerinin gelişimine bağlı ve başarının üst sınırlarının kalıtımla belirlendiğini savunur. Bu yaklaşıma statik yetenek anlayışı denir.

Dinamik yetenek anlayışında ise bireyin kalıtsal özelliklerinin geliştirilmesi, eğitilmesi ile elde edilen potansiyelidir ve sonradan kazanılan yetenektir. Ham yeteneğin eğitim sürecini etkileyen faktörleri de çevresel faktörler (aile, okul, arkadaş, coğrafik, çevre, iklimler, yaşam koşulları) olarak kabul edilir. Dinamik yetenek anlayışını benimseyenler, spor yeteneğinin kalıtımsal özellikler ile çevre şartlarının sıkı ilişkisine dayandığı görüşünü savunurlar. Bu sebeple; yetenek, doğuştan garantilenmiş kabul edilmemektedir. Çünkü bir yeteneği belirleyen bileşenler gelişebilir veya gelişmeyebilir. Yetenek, sporcunun başarısında kendini gösterir, ama başarıyla eş anlamlı değildir. Yaş dönemlerindeki gelişimin de dikkate alınması gerekir. Çünkü olgunlaşma; vücut kompozisyonunu, motorik ve antropometrik özelliklerini de etkileyebilmektedir. Antrenman biliminde yetenek şimdilik dinamik bir kavram olarak kabul edilmekte yeteneğin doğuştan itibaren sabit olmadığ 1 kabul edilmektedir. Yeteneğin bileşenleri olan beceriler, gelişebilir, ancak gelişmek zorunda da değildir (Muratlı, 2007).

Spor eğitimi ile ilgili temel bilgi ve becerilerin kazandırılması ve alanlarında başarılı bireylerin yetişmesine olanak sağlamak amacı ile kurulan spor liseleri, yeteneğin ortaya konmasında bireyin çevre ile etkileşimini, uygun olanaklar ile buluşmasını sağlayacak nitelikteki okullardır. Spor liseleri öğrenci seçme sınavlarında sportif yetenekle ilgili; koordinasyon parkuru, durarak uzun atlama, sürat, ritim testleri, spor öz geçmişi gibi çeşitli kriterler koyarken, bilişsel süreçlerdeki başarı düzeyini de; akademik başarı puanı ile belirlemektedir. Bu liseler sportif ve akademik başarısı yüksek olan yani yetenekli ve başarılı öğrencileri seçmek istemektedirler. Orta öğretim düzeyindeki öğrenciler hareketsel gelişim dönemlerinden; özel hareket becerileri evresi ve spor dalına özgü hareket becerileri evresindedirler. Özel hareket becerileri evresi ortalama 11-13 yaş arası çocukları kapsar ve bu evrede bireysel farklı1ıklar, branşa yönelme isteği ortaya çıkar. Büyümenin en hızlı olduğu dönemde kız çocuklarında motor öğrenme hiçbir zaman erişemeyeceği düzeye erişir. Erkek çocuklarında ise motor öğrenme yeteneği bu yaşların 
sonuna kadar büyük ölçüde aynı kalır. Spor ile ilgili motor gelişim evresinde spor dalına özgü hareket gelişimi yaklaşık olarak 14 yaşında başlar ve olgunluk dönemince devam eder. Branşlaşma gelişim evresinin en üst basamağıdır ve çocuğun ilgi duyduğu yetenekleri ile uyum içerisinde olduğu branş seçimi yapılır. Bu dönemde çocuk nöro-muskuler sistem yönünden gelişir ve karmaşık hareketler uygun biçimlerde yapılabilir. Araştırmacılar tarafından orta öğretim dönemine denk gelen zaman aralığında bazı motor beceriler ile ilgili norm değerler verilmiştir. Hoffman (2006) durarak uzun atlama norm değerleri 15-16 yaş grubu erkeklerde ortalama $(176 \mathrm{~cm})$, çok iyi $(186 \mathrm{~cm})$ ve en iyi dereceleri $(201 \mathrm{~cm})$, kadınlarda; ise $(146 ; 156 ; 166$ cm) olarak Davis ve diğerleri (2000) 16-19 yaş arası erkeklerde ve kadınlarda sırası ile 30 metre sprint performasını ortalama $(4,4-4,3 \mathrm{sn} ; 4,8-4,7)$ çok iyi $(4,2-4,00 ; 4,6-4,5)$ ve en iyi $(<4.0 ;<4,5)$ olarak belirtmişlerdir. Araştırmaya konu olan spor lisesinde koordinasyon parkuru, 30 metre sprint, durarak uzun atlama ve ritim testleri ve sportif özgeçmiş puanları belirlenerek kazanma yada elenme durumları belirlenmiştir.

Araştırmanın amacı spor lisesi yetenek sınavına katılan adayların sınavı kazanarak okula yerleşme ve kazanamama durumlarının hangi sportif parametrelerden kaynaklandığının ve akademik başarının kazanma durumuna etkisini belirlemektir.

\section{Yöntem}

Çalışma 2017-2018 öğretim yılında spor lisesi yetenek sınavına giren 206 (erkek:152; kadın:54) kişi arasından sınavı kazanan $n=101$ (erkek:67 kadın:34) ve kazanamayan $n=105$ ( $n=20$ kadın; $n=85$ erkek) aday ile gerçekleştirilmiş çeşitli sebeplerle sportif testlere girmeyen veya terk eden 4 kadın ve 5 erkek aday araştırma dışında tutulmuştur. Yetenek sınavına giren öğrenciler; koordinasyon parkuru, $30 \mathrm{~m}$ sürat, durarak uzun atlama, ritim testlerine katılarak derecelerine göre puan almışlardır.

Yetenek sınavı sonucu değerlendirilirken 30 metre sürat (20 puan), koordinasyon (45 puan), durarak uzun atlama (10 puan), ritim (10 puan), sportif özgeçmiş (15 puan) olacak şekilde puanlanmıştır. Yetenek sınavını kazanan ve kazanamayan öğrencilerin cinsiyete göre yetenek testlerindeki puanları belirlenmiştir. Yetenek testleri sonucunda 50 puan barajını geçemeyen adaylar elenmiştir. Ayrıca adaylar sportif yetenek test puanları dağılımına göre en yüksek ve en düşük değerler dikkate alınarak 3 kategoriye ayrılmıştır. Sportif yetenek test puanları siralamasına göre erkekler $(1$.grup $=0-28,40 ; 2$.grup $=28,41-56,80 ; 3$.grup $=56,81-85,37$ puan $)$ ve kadın adaylar (1. grup=11,00-39,73; 2.grup=39,74-68,47; 3.grup=68,48-97,21 puan) olmak üzere 3 gruba ayrılmıştır. 
Verilerin analizinde normallik sınamaları yapılmış, normal dağılım göstermedikleri belirlenmiştir. Sınavı kazanan ve kazanamayan kadın ve erkek adayların yetenek test puanları arasındaki farklılığı belirlemek için ikili karşılaştırmalarda Mann-Whitney U testi kullanılmıştır. Sportif yetenek test puanlarına göre yapılan gruplar arası karşılaştırmada fark olup olmadığını belirlemek amacıyla Kruskal Vallis testi, kullanılmıştır. İstatistiksel anlamlılık düzeyi $\mathrm{p}<0,05$ olarak kabul edilmiştir.

30 metre sürat: 30 metre süratinin belirlenmesinde saniyenin yüzde birini kaydedilebilen elektronik Prosport TMR ESC 2100 telemetrik kronometre (Türkiye) kullanılmıştır. Hız ölçümü, spor salonunda 30 metrelik mesafe belirlenerek ölçülmüştür. $30 \mathrm{~m}$ hız koşusu testinde süreyi fotosel giriş kapısından geçmesiyle adayın kendisi başlamış ve çıkış kısmından geçmesiyle yine kendisi bitirmiştir. Testin başlangıcını ve bitişini aday performansıyla kendisi belirlemiştir. Adaya fotoselin $1 \mathrm{~m}$ gerisindeki işaretlenmiş olan çizgiye basarak çıkış yaptırılmıştır.

Koordinasyon: Adayların farklı motorik özelliklerini test eden istasyonlardan oluşmaktadır. Parkur içerisinde her istasyonun tam ve doğru olarak yapılması gerekmektedir. Aday herhangi bir istasyonda hata yaptığında uyarılarak hatalı bölümün başına tekrar göndermiştir. Koordinasyon parkuru minderde öne takla, denge, engelin altından ve üzerinden geçiş, file üzerinden topu geçirme, hentbol topu ile duvarda pas, yana sıçrama, basketbol topları ile yerden slalom geçiş istasyonlarından oluşmaktadır.

Durarak uzun atlama (DUA): Ayakta hız almadan duruş pozisyonundan çift bacak birbiri ile bağlantılı yapılan uzun atlama sonunda sıçrama noktasındaki çizgi ile sporcunun en son iz bıraktığı mesafe arası cm cinsinden ölçülmüştür. Test iki defa tekrar edilmiş ve en iyi sonuç kaydedilmiştir (Sevim, 1997).

Ritim testi: Adaylardan, sınav komisyon üyelerinin (3 kişi) elleri, ağızları ve herhangi bir nesneyle birlikte veya ayrı ayrı verdiği çeşitli ritimleri aynı hızda ve doğrulukta uyum içerisinde tekrar etmesi istenmiştir. Verilen ritimleri aynı uyum, hız ve doğrulukta yapma düzeylerine göre adaylara her komisyon üyesi tarafından 10 üzerinden verilen puanların ortalaması alınmış ve bu testten alınan puan 10 üzerinden değerlendirilmiştir. Ritim testinin Yetenek Sınav Puanına (YSP) katkısı \%10 üzerinden değerlendirilmiştir.

Sportif Özgeçmiş Puanı (SÖP): Adayların sportif özgeçmişlerini Gençlik ve Spor Bakanlığg'ndan, ilgili Federasyonlardan, Okul Sporları Federasyonundan veya Gençlik Hizmetleri ve Spor İl Müdürlüklerinden (GHSIM) resmi olarak belgelendirerek ön kayıt sırasında beyan etmeleri sağlanmıştır. 
Akademik Başarı Puanı (ABP): 2017-2018 eğitim öğretim yılında özel yetenek sınavı sırasında Milli Eğitim Bakanlığı'nın ilgili web sayfasından alınan sınav sonuç belgesinden elde edilmiştir.

\section{Akademik başarı sınav puanı hesaplaması}

Akademik başarı sınav puanı 100'lük sisteme dönüştürülüp bu puanın \%30’u alınmıştır.

Akademik başarı sınav puanı / 5 = Yüzlük Sisteme Dönüştürülmüş Puan hesaplanır.

Yetenek Sınav Puanı (YSP) hesaplaması: Her test için en iyi derece yapan öğrencilerin alacakları maksimum puan testlerin yanlarında belirtilmiştir ve testlerden alınacak toplam puan 100 olarak hesaplanmıştır. Testlerdeki başarı seviyesine göre katılımcılara puan verilmiştir. 30 metre sürat testi (20 puan), koordinasyon parkuru (45 puan), durarak uzun atlama mesafesi (10 puan), ritim testi (10 puan) ve sportif özgeçmiş (15 puan) olacak şekilde hesaplanmıştır.

Yerleştirme Puanı (YP) hesaplaması: Akademik başarı puanının yüzlük sisteme dönüştürüldükten sonra \%30'u ve yetenek sınav puanının \%70'i alınarak toplanmıştır. Akademik başarı \%30+YSP $\% 70=$ YP

\section{Bulgular}

Tablo 1: Adayların Cinsiyete Göre Yaş Dağılımlarının Maksimum, Minimum, Ortalama ve Standart Sapma Değerleri

\begin{tabular}{lllllllll}
\hline & \multicolumn{7}{c}{ Erkek n=152 } & \multicolumn{6}{c}{ Kadın n=54 } \\
\hline Yaş (y11) & Min. & Mak. & Ort. & Ss & Min. & Mak. & Ort. & Ss \\
& 14 & 17 & 14,27 & 0,58 & 14 & 16 & 14,29 & 0,50 \\
\hline
\end{tabular}

Tablo 2: Spor Lisesi Sınavına Giren Kazanan ve Elenen Erkek Adayların Yaş, Akademik Başarı Puanı, Koordinasyon, 30 M Sprint, Durarak Uzun Atlama, Ritim Puanı, Sportif Özgeçmiş Puanı, Yetenek Sınav Puanı,, Yerleştirme Puanlarının Ortalamaları Ve Standart Sapma Değerleri

\begin{tabular}{lllll}
\hline Değişkenler & Yerleşme Durumu & $\mathrm{N}$ & $\overline{\mathrm{X}}$ & $\boldsymbol{S S}$ \\
\hline \multirow{2}{*}{ Yaş (yı1) } & Kazandı & 67 & 14,33 & 0,61 \\
& Elendi & 85 & 14,24 & 0,57 \\
\hline \multirow{2}{*}{ ABP } & Kazandı & 67 & 276,04 & 53,25 \\
& Elendi & 85 & 251,25 & 48,76 \\
\hline \multirow{2}{*}{ Koordinasyon (sn) } & Kazandı & 67 & 47,37 & 2,68 \\
& Elendi & 85 & 57,24 & 7,07 \\
\hline \multirow{2}{*}{30 metre sprint $(\mathrm{sn})$} & Kazandı & 67 & 4,36 & 0,17 \\
& Elendi & 85 & 4,78 & 0,32 \\
\hline \multirow{2}{*}{ DUA (cm) } & Kazandı & 67 & 2,09 & 0,15 \\
& Elendi & 85 & 1,80 & 0,20 \\
\hline \multirow{2}{*}{ Ritim puanı } & Kazandı & 67 & 9,79 & 0,45 \\
& Elendi & 85 & 9,69 & 0,56 \\
\hline
\end{tabular}




\begin{tabular}{lllll} 
SÖP & Kazand 1 & 67 & 2,64 & 3,77 \\
& Elendi & 85 & 0,96 & 2,68 \\
\hline YSP & Kazand 1 & 67 & 64,21 & 9,19 \\
& Elendi & 85 & 30,57 & 13,02 \\
\hline YP & Kazandı & 67 & 61,51 & 7,09 \\
& Elendi & 85 & 0,00 & 0,00 \\
\hline
\end{tabular}

Tablo 3: Spor Lisesi Sinavına Giren Erkek Adayların Puan Ortalamalarının Sınavı Kazanma ve Elenme Değişkenine Göre Farklılaşıp Farklılaşmadığını Belirlemek Üzere Yapılan Mann Whitney U Testi Sonuçları

\begin{tabular}{|c|c|c|c|c|c|c|}
\hline Değişkenler & Erkekler & $\mathrm{SO}$ & ST & $\mathrm{U}$ & $\mathrm{Z}$ & $p$ \\
\hline \multirow{2}{*}{$\mathrm{ABP}$} & Kazand1:67 & 47,97 & 1679,00 & \multirow{2}{*}{1049} & \multirow{2}{*}{,- 75} & \multirow{2}{*}{,449 } \\
\hline & Elendi:85 & 52,61 & 3472,00 & & & \\
\hline \multirow{2}{*}{ Koordinasyon (sn) } & Kazand1:67 & 81,71 & 2860,00 & \multirow{2}{*}{80,00} & \multirow{2}{*}{$-7,67$} & \multirow{2}{*}{, 000} \\
\hline & Elendi:85 & 34,71 & 2291,00 & & & \\
\hline \multirow{2}{*}{30 metre sprint (sn) } & Kazand1:67 & 70,56 & 2469,50 & \multirow{2}{*}{470,50} & \multirow{2}{*}{$-4,88$} & \multirow{2}{*}{,000 } \\
\hline & Elendi:85 & 40,63 & 2681,50 & & & \\
\hline \multirow{2}{*}{ DUA (cm) } & Kazand1:67 & 29,83 & 1044,00 & \multirow{2}{*}{414,00} & \multirow{2}{*}{$-5,29$} & \multirow{2}{*}{, 000} \\
\hline & Elendi:85 & 62,23 & 4107,00 & & & \\
\hline \multirow{2}{*}{ Ritim puanı } & Kazand1:67 & 51,16 & 1790,50 & \multirow{2}{*}{1150} & \multirow{2}{*}{3360} & \multirow{2}{*}{$-0,52$} \\
\hline & Elendi:85 & 50,92 & 3360,50 & & & \\
\hline \multirow{2}{*}{ SÖP } & Kazand1:67 & 47,19 & 1651,50 & \multirow{2}{*}{1021,5} & \multirow{2}{*}{$-1,63$} & \multirow{2}{*}{, 001} \\
\hline & Elendi:85 & 53,02 & 3499,50 & & & \\
\hline \multirow{2}{*}{ YSP } & Kazand1:67 & 18,00 & 630,00 & \multirow{2}{*}{, 000} & \multirow{2}{*}{$-8,24$} & \multirow{2}{*}{, 000} \\
\hline & Elendi:85 & 68,50 & 4521,00 & & & \\
\hline \multirow{2}{*}{ YP } & Kazandı:67 & 43,00 & 1505,00 & \multirow{2}{*}{875,00} & \multirow{2}{*}{$-3,14$} & \multirow{2}{*}{, 002} \\
\hline & Elendi:85 & 55,24 & 3646,00 & & & \\
\hline
\end{tabular}

$\mathrm{p}<0,05$

Sınavı kazanan erkek adaylar elenenler ile karşılaştırıldığında, koordinasyon parkuru, $30 \mathrm{~m}$ sprint, durarak uzun atlama, sportif özgeçmiş, yetenek ve yerleştirme puanları arasında istatistiksel olarak kazananlar lehine anlamlı fark belirlenmiştir. Sınavı kazanan adayların akademik başarı puanları ve sportif testlerdeki başarıları kazanamayan adaylardan yüksektir. 
Tablo 4: Spor Lisesi Sınavına Giren Kazanan ve Elenen Kadın Adayların Yaş, ABP, Koordinasyon, 30m Sprint, DUA, Ritim Puanı, SÖB, YSP, YP Ortalamaları ve Standart Sapma Değerleri

\begin{tabular}{|c|c|c|c|c|}
\hline Değişkenler & Yerleşme Durumu & $\mathrm{N}$ & $\overline{\mathrm{X}}$ & $S S$ \\
\hline \multirow{2}{*}{ Yaş (y1l) } & Kazand 1 & 34 & 14,24 & 0,43 \\
\hline & Elendi & 20 & 14,40 & 0,60 \\
\hline \multirow{2}{*}{$\mathrm{ABP}$} & Kazand 1 & 34 & 278,69 & 55,68 \\
\hline & Elendi & 20 & 287,90 & 46,29 \\
\hline \multirow{2}{*}{ Koordinasyon (sn) } & Kazand 1 & 34 & 54,77 & 3,89 \\
\hline & Elendi & 20 & 66,24 & 7,07 \\
\hline \multirow{2}{*}{30 metre sprint (sn) } & Kazand 1 & 34 & 5,05 & 0,30 \\
\hline & Elendi & 20 & 5,32 & 0,28 \\
\hline \multirow{2}{*}{ DUA $(\mathrm{cm})$} & Kazand1 & 34 & 1,71 & 0,18 \\
\hline & Elendi & 20 & 1,59 & 0,15 \\
\hline \multirow{2}{*}{ Ritim puanı } & Kazand 1 & 34 & 9,85 & 0,36 \\
\hline & Elendi & 20 & 9,80 & 0,52 \\
\hline \multirow{2}{*}{ SÖP } & Kazand 1 & 34 & 4,38 & 4,79 \\
\hline & Elendi & 20 & 0,00 & 0,00 \\
\hline \multirow{2}{*}{ YSP } & Kazand 1 & 34 & 68,88 & 12,75 \\
\hline & Elendi & 20 & 37,14 & 11,29 \\
\hline \multirow{2}{*}{ YP } & Kazand1 & 34 & 64,94 & 9,93 \\
\hline & Elendi & 20 & 0,00 & 0,00 \\
\hline
\end{tabular}

Tablo 5: Spor Lisesi Sinavına Giren Kadın Adayların Puan Ortalamalarının Sinavı Kazanma ve Elenme Değişkenine Göre Farklılaşıp Farklılaşmadığını Belirlemek Üzere Yapılan Mann Whitney U Testi Sonuçları

\begin{tabular}{|c|c|c|c|c|c|c|}
\hline Değişkenler & Kadınlar & SO & ST & $\mathrm{U}$ & $\mathrm{Z}$ & $p$ \\
\hline \multirow{2}{*}{$\mathrm{ABP}$} & Kazand1:34 & 26,3 & 895,00 & \multirow{2}{*}{300,00} & \multirow{2}{*}{$-0,72$} & \multirow{2}{*}{0,47} \\
\hline & Elendi:20 & 29,5 & 590,00 & & & \\
\hline \multirow{2}{*}{ Koordinasyon (sn) } & Kazand1:34 & 17,7 & 602,00 & \multirow{2}{*}{7,00} & \multirow{2}{*}{$-5,97$} & \multirow{2}{*}{0,00} \\
\hline & Elendi:20 & 44,2 & 883,00 & & & \\
\hline \multirow{2}{*}{30 metre sprint (sn) } & Kazand1:34 & 22,3 & 758,50 & \multirow{2}{*}{163,50} & \multirow{2}{*}{$-3,16$} & \multirow{2}{*}{0,00} \\
\hline & Elendi:20 & 36,3 & 726,50 & & & \\
\hline \multirow{2}{*}{ DUA (cm) } & Kazand1:34 & 31,4 & 1069,00 & \multirow{2}{*}{206,00} & \multirow{2}{*}{$-2,4$} & \multirow{2}{*}{0,02} \\
\hline & Elendi:20 & 20,8 & 416,00 & & & \\
\hline \multirow{2}{*}{ Ritim puan1 } & Kazandı:34 & 27,6 & 938,50 & \multirow{2}{*}{336,50} & \multirow{2}{*}{$-0,10$} & \multirow{2}{*}{0,92} \\
\hline & Elendi:20 & 27,3 & 546,50 & & & \\
\hline \multirow{2}{*}{ SÖP } & Kazand1:34 & 32,5 & 1105,00 & \multirow{2}{*}{2379,00} & \multirow{2}{*}{$-2,82$} & \multirow{2}{*}{0,01} \\
\hline & Elendi:20 & 19,0 & 380,00 & & & \\
\hline \multirow{2}{*}{ YSP } & Kazand1:34 & 37,5 & 1275,00 & \multirow{2}{*}{0,00} & \multirow{2}{*}{$-6,09$} & \multirow{2}{*}{0,00} \\
\hline & Elendi:20 & 10,5 & 210,00 & & & \\
\hline \multirow{2}{*}{ YP } & Kazand1:34 & 37,5 & 1275,00 & \multirow{2}{*}{0,00} & \multirow{2}{*}{$-6,25$} & \multirow{2}{*}{0,00} \\
\hline & Elendi:20 & 10,5 & 210,00 & & & \\
\hline
\end{tabular}


Sınavı kazanan kadın adaylar elenenler ile karşılaştırıldığında akademik başarı puanı ve ritim puanı değerlerinde istatistiksel olarak anlamlı farklılık bulunmazken koordinasyon parkuru, 30 m sprint, durarak uzun atlama, sportif özgeçmiş, yetenek ve yerleştirme puanları arasında sınavı kazanan adaylar lehine istatistiksel olarak anlamlı fark tespit edilmiştir. Sınavı kazanan kadın adayların sportif testlerdeki başarıları kazanamayan adaylara göre daha yüksektir.

Tablo 6: Kategorik Sportif Başarı Puan Değişkenine Göre Erkek Adayların Sportif ve Akademik Başarılarının Farklılaşıp Farklılaşmadığını Belirlemek Üzere Yapılan Kruskal Wallis-H Testi Sonuçları

\begin{tabular}{|c|c|c|c|c|c|c|c|}
\hline Değişkenler & Puan aralığı & Farklar & $N$ & $\bar{x}_{\text {sira }}$ & $x^{2}$ & $s d$ & $p$ \\
\hline & $\mathrm{G}_{1}: 0,00-28,40$ & & 35 & 66,86 & & & \\
\hline \multirow[t]{3}{*}{$\mathrm{ABP}$} & $\mathrm{G}_{2}: 28,41-56,80$ & & 66 & 73,77 & 4,64 & 2 & 0,10 \\
\hline & $\mathrm{G}_{3}: 56,81-85,10$ & & 51 & 86,65 & & & \\
\hline & $\mathrm{G}_{1}: 0,00-28,40$ & $\mathrm{G}_{2}>\mathrm{G}_{1}$ & 35 & 132,71 & & & \\
\hline \multirow[t]{3}{*}{ Koordinasyon (sn) } & $\mathrm{G}_{2}: 28,41-56,80$ & $\mathrm{G}_{3}>\mathrm{G}_{2}$ & 66 & 81,7 & 112 & 2 & 0,00 \\
\hline & $\mathrm{G}_{3}: 56,81-85,10$ & $\mathrm{G}_{3}>\mathrm{G}_{1}$ & 51 & 31,19 & & & \\
\hline & $\mathrm{G}_{1}: 0,00-28,40$ & $\mathrm{G}_{2}>\mathrm{G}_{1}$ & 35 & 119,33 & & & \\
\hline \multirow[t]{3}{*}{30 metre sprint (sn) } & $\mathrm{G}_{2}: 28,41-56,80$ & $\mathrm{G}_{3}>\mathrm{G}_{2}$ & 66 & 85,57 & 80,46 & 2 & 0,00 \\
\hline & $\mathrm{G}_{3}: 56,81-85,10$ & $\mathrm{G}_{3}>\mathrm{G}_{1}$ & 51 & 35,37 & & & \\
\hline & $\mathrm{G}_{1}: 0,00-28,40$ & $\mathrm{G}_{2}>\mathrm{G}_{1}$ & 35 & 31,06 & & & \\
\hline \multirow[t]{3}{*}{ DUA (cm) } & $\mathrm{G}_{2}: 28,41-56,80$ & $\mathrm{G}_{3}>\mathrm{G}_{2}$ & 66 & 69,41 & 81,91 & 2 & 0,00 \\
\hline & $\mathrm{G}_{3}: 56,81-85,10$ & $\mathrm{G}_{3}>\mathrm{G}_{1}$ & 51 & 116,86 & & & \\
\hline & $\mathrm{G}_{1}: 0,00-28,40$ & & 35 & 75,1 & & & \\
\hline \multirow[t]{3}{*}{ Ritim puanı } & $\mathrm{G}_{2}: 28,41-56,80$ & & 66 & 74,86 & 0,706 & 2 & 0,70 \\
\hline & $\mathrm{G}_{3}: 56,81-85,10$ & & 51 & 79,59 & & & \\
\hline & $\mathrm{G}_{1}: 0,00-28,40$ & & 35 & 64,00 & & & \\
\hline \multirow[t]{3}{*}{ SÖP } & $\mathrm{G}_{2}: 28,41-56,80$ & $\mathrm{G}_{3}>\mathrm{G}_{2}$ & 66 & 73,36 & 14,23 & 2 & 0,00 \\
\hline & $\mathrm{G}_{3}: 56,81-85,10$ & $\mathrm{G}_{3}>\mathrm{G}_{1}$ & 51 & 89,14 & & & \\
\hline & $\mathrm{G}_{1}: 0,00-28,40$ & $\mathrm{G}_{2}>\mathrm{G}_{1}$ & 35 & 43 & & & \\
\hline \multirow[t]{2}{*}{ YP } & $\mathrm{G}_{2}: 28,41-56,80$ & $\mathrm{G}_{3}>\mathrm{G}_{2}$ & 66 & 55,91 & 120,6 & 2 & 0,00 \\
\hline & $\mathrm{G}_{3}: 56,81-85,10$ & $\mathrm{G}_{3}>\mathrm{G}_{1}$ & 51 & 126,14 & & & \\
\hline
\end{tabular}

$\mathrm{G}_{1}$ : Grup 1; $\mathrm{G}_{2}$ : Grup 2; $\mathrm{G}_{3}$ : Grup 3 p $<0,05$

Kategorik sportif başarı puanına göre erkek adayların akademik başarı ve ritim puanı değerlerinde istatistiksel olarak anlamlı farklılık belirlenmemiş ancak koordinasyon parkuru, 30 m sprint, durarak uzun atlama, sportif özgeçmiş düzeyleri ve yerleştirme puanları arasında istatistiksel olarak anlamlı fark tespit edilmiştir. En yüksek sportif başarı puanına sahip olan 3. 
grup; koordinasyon parkuru, $30 \mathrm{~m}$ sprint derecesi, durarak uzun atlama, sportif özgeçmiş puanları ve yerleştirme puanları diğer gruplardan yüksektir.

Tablo 7: Kategorik Sportif Başarı Puan Değişkenine Göre Kadın Adayların Sportif ve Akademik Başarılarının Farklılaşıp Farklılaşmadığını Belirlemek Üzere Yapılan Kruskal Wallis-H Testi Sonuçları

\begin{tabular}{|c|c|c|c|c|c|c|c|}
\hline Değişkenler & Puan aralığ 1 & & $\mathrm{~N}$ & $\bar{x}_{\text {sira }}$ & $x^{2}$ & $s d$ & $p$ \\
\hline \multirow{3}{*}{$\mathrm{ABP}$} & $\mathrm{G}_{1}: 11,00-39,73$ & & 8 & 26,6 & \multirow{3}{*}{0,03} & \multirow{3}{*}{2} & \multirow{3}{*}{0,99} \\
\hline & $\mathrm{G}_{2:} 39,74-68,47$ & & 28 & 27,6 & & & \\
\hline & $\mathrm{G}_{3: 68,48-97,21}$ & & 18 & 27,7 & & & \\
\hline \multirow{3}{*}{ Koordinasyon (sn) } & $\mathrm{G}_{1}: 11,00-39,73$ & $\mathrm{G}_{2}>\mathrm{G}_{1}$ & 8 & 48,5 & \multirow{3}{*}{32,9} & \multirow{3}{*}{2} & \multirow{3}{*}{0,00} \\
\hline & $\mathrm{G}_{2: 39,74-68,47}$ & $\mathrm{G}_{3}>\mathrm{G}_{2}$ & 28 & 31,3 & & & \\
\hline & $\mathrm{G}_{3: 68,48-97,21}$ & $\mathrm{G}_{3}>\mathrm{G}_{1}$ & 18 & 12,2 & & & \\
\hline \multirow{3}{*}{30 metre sprint (sn) } & $\mathrm{G}_{1}: 11,00-39,73$ & $\mathrm{G}_{2}>\mathrm{G}_{1}$ & 8 & 43,9 & \multirow{3}{*}{25} & \multirow{3}{*}{2} & \multirow{3}{*}{0,00} \\
\hline & $\mathrm{G}_{2}: 39,74-68,47$ & $\mathrm{G}_{3}>\mathrm{G}_{2}$ & 28 & 31,8 & & & \\
\hline & $\mathrm{G}_{3: 68,48-97,21}$ & $\mathrm{G}_{3}>\mathrm{G}_{1}$ & 18 & 13,6 & & & \\
\hline \multirow{3}{*}{ DUA (cm) } & $\mathrm{G}_{1}: 11,00-39,73$ & $\mathrm{G}_{2}>\mathrm{G}_{1}$ & 8 & 12,8 & \multirow{3}{*}{24,6} & \multirow{3}{*}{2} & \multirow{3}{*}{0,00} \\
\hline & $\mathrm{G}_{2:} 39,74-68,47$ & $\mathrm{G}_{3}>\mathrm{G}_{2}$ & 28 & 22,5 & & & \\
\hline & $\mathrm{G}_{3: 68,48-97,21}$ & $\mathrm{G}_{3}>\mathrm{G}_{1}$ & 18 & 41,8 & & & \\
\hline \multirow{3}{*}{ Ritim } & $\mathrm{G}_{1}: 11,00-39,73$ & & 8 & 24,4 & \multirow{3}{*}{1,05} & \multirow{3}{*}{2} & \multirow{3}{*}{0,59} \\
\hline & $\mathrm{G}_{2:} 39,74-68,47$ & & 28 & 27,7 & & & \\
\hline & $\mathrm{G}_{3: 68,48-97,21}$ & & 18 & 28,6 & & & \\
\hline \multirow{3}{*}{ SÖP } & $\mathrm{G}_{1}: 11,00-39,73$ & & 8 & 19 & \multirow{3}{*}{16,7} & \multirow{3}{*}{2} & \multirow{3}{*}{0,00} \\
\hline & $\mathrm{G}_{2}: 39,74-68,47$ & $\mathrm{G}_{3}>\mathrm{G}_{2}$ & 28 & 23,6 & & & \\
\hline & $\mathrm{G}_{3: 68,48-97,21}$ & $\mathrm{G}_{3}>\mathrm{G}_{1}$ & 18 & 37,4 & & & \\
\hline \multirow{3}{*}{ YP } & $\mathrm{G}_{1}: 11,00-39,73$ & $\mathrm{G}_{2}>\mathrm{G}_{1}$ & 8 & 10,5 & \multirow{3}{*}{38} & \multirow{3}{*}{2} & \multirow{3}{*}{0,00} \\
\hline & $\mathrm{G}_{2: 39,74-68,47}$ & $\mathrm{G}_{3}>\mathrm{G}_{2}$ & 28 & 21,1 & & & \\
\hline & $\mathrm{G}_{3: 68,48-97,21}$ & $\mathrm{G}_{3}>\mathrm{G}_{1}$ & 18 & 44,9 & & & \\
\hline
\end{tabular}

Kategorik sportif başarı puanına göre kadın adayların akademik başarı ve ritim puanı değerlerinde istatistiksel olarak anlamlı farklılık belirlenmezken, koordinasyon parkuru, $30 \mathrm{~m}$ sprint, durarak uzun atlama, sportif özgeçmiş puanları ve yerleştirme puanları arasında istatistiksel olarak anlamlı fark tespit edilmiştir. En yüksek sportif başarı puanına sahip olan 3 . grup; koordinasyon parkuru, $30 \mathrm{~m}$ sprint, durarak uzun atlama, sportif özgeçmiş puanları ve yerleştirme puanları diğer gruplardan yüksektir. 


\section{Tartışma ve Sonuç}

$\mathrm{Bu}$ çalışma, 2017-2018 öğretim yılında spor lisesi yetenek sınavına girerek başarılı olup kayıt yaptırma hakkı kazanan ve başarısız olup elenen öğrencilerin yetenek testlerindeki başarı puan farklılıklarını karşılaştırmak ve bu farklılığın hangi parametrelerde olduğunun belirlemek amacıyla yapılmıştır.

Yapılan çalışmada spor lisesi yetenek sınavını kazanarak okula yerleşme hakkı elde eden kadın ve erkek adayların akademik ve sportif başarıları diğer adaylara göre daha yüksektir. Ancak erkek adaylar ile kadın adaylar arasında spor lisesine yerleşme oranında farklı parametreler etkili olmuştur. Adayların okula yerleşme değerlendirmesine girebilmeleri için yetenek test uygulamasından en az 50 puan barajını geçmeleri gerekmektedir. Erkek adaylar arasında bu barajı aşan kişi sayısı kadın adaylardan fazladır. Kadın adaylar arasından yetenek test puanında 50 barajını geçenlerin tamamı spor lisesine kayıt yaptırma hakkı kazanmıştır. Erkek adaylar arasından 50 barajını başarı ile geçenlerin spor liselerine yerleşmesinde akademik başarı puanı belirleyici olmuştur. Spor lisesini kazanan yetenekli öğrencilerin akademik başarıları da yüksektir. Literatür akademik başarı ile sportif başarı arasında olumlu (Tosun, Demir, Uçkun, \& Konak, 2015), olumsuz (Alvurdu \& Şenel, 2010; Mücevher, Demirgil, \& Erdem, 2015) ve etkisiz (Bayraktar, 1999) olmak üzere farklı sonuçlar ortaya koymuştur. Yapılan çalışmada sportif başarısı yüksek olan adayların akademik başarıları da yüksektir. Yetenekli sporcuların akademik başarılarının da yüksek olması sebebiyle akademik çalışmalara spor uygulamalarının olumlu şekilde etkisi olduğunu belirten çalışmalar ile benzer sonuca varılmıştır.

Yapılan çalışmada sınavı kazanarak okula yerleşen adayların koordinasyon parkuru derecesi (erkek: 47,37 sn; kadın 54,77 sn), 30 metre sürat derecesi ortalaması (erkek 4.36 sn; kadın 5.05 sn), durarak uzun atlama derecesi (erkeklerde 2,09 m; kadınlarda $1.71 \mathrm{~m}$ ) olarak belirlenmiştir. Literatür incelendiğinde Taşkın ve diğerleri (2015 )yaşları ortalaması 14.40 yıl olan sporcuların 30 metre sürat performansı ortalaması $5.52 \mathrm{sn}$, durarak uzun atlama ortalama değerini 184.70 cm, Göral ve Göral, (2015) futbolcu kadınların 30 metre sprint değeri 5.65 sn olarak, Diker ve Müniroğlu (2016) yaş grubu 13.06 yıl olan futbolcu çocukların $30 \mathrm{~m}$ sprint değerini $5.0 \mathrm{sn}$, durarak uzun atlama değerini 1.6 m olarak Özsu (2011), yaşları 12-14 arasında olan sporcuların 30 metre sprint derecesini kadınlarda 4.67 sn, erkeklerde 4.70 sn olarak, durarak uzun atlama mesafesini kadınlarda 1,93 m, erkeklerde 2,01 m olarak belirtirlerken, Cicioğlu ve diğerleri (1996) 14-15 yaş grubu basketbolcuların durarak uzun atlama mesafelerini $2.03 \mathrm{~cm}$ olarak belirtmişlerdir. Bu veriler spor lisesini kazanan öğrencilerin kendi yaş gruplarındaki 
sporculara benzer durarak uzun atlama değerlerine ve daha iyi sprint performansı özelliklere sahip olduklarını göstermektedir.

Koordinasyon (beceri), kısa süre içerisinde zor hareketleri öğrenebilme ve değişik durumlarda amaca uygun ve çabuk bir biçimde tepki gösterebilme yeteneğidir (Günay \& Yüce, 2008). Spor lisesi sınavlarında öğrencilerin koordinasyon derecesi fiziki şartlara (istasyon sayısı ve istasyonlar arası mesafe farkı) bağlı olarak değişebilir. Spor liselerinin uyguladıkları koordinasyon parkurları farklı istasyonlardan oluştuğu için literatürdeki koordinasyon sınav sonuçları ile tartışılamamıştır.

Sonuç olarak, çocukları bir bütün olarak değerlendirip, zorunlu eğitimden sonra ilgi ve yeteneklerini ön planda tutarak hem yükseköğrenime hem de meslek alanlarına hazırlanması sağlanmalıdır. Akademik başarısı ve sportif başarısı yüksek yetenekli gençlerin spor liselerine teşvik edilmesi eğitim ve sporcu kalitesini arttıracağı söylenebilir. Ayrıca, spor liselerinde yetenek sınavına girerek yerleşmek isteyen kadın adaylara yetenek testlerindeki başarılarını, erkek adaylara ise akademik başarılarını attırıcı şekilde çalışmaları önerilebilir.

\section{Kaynaklar}

Alvurdu, S., \& Şenel, Ö. (2010). Lise Eğitimi Sürecindeki Futbolcu Öğrencilerin Sorunları (Ankara İli Örneği). Spormetre Beden Eğitimi ve Spor Bilimleri Dergisi, VIII(1), 17-28.

Bayraktar, C. (1999). Spor Yapan Öğrenciler İle Spor Tapmayan Öğrencilerin Uyum ve Derslerindeki Başarı Düzeylerinin Karşılaştırılması. (Yayımlanmamış Doktora Tezi), Marmara Üniversitesi Sağllk Bilimleri Enstitüsü, İstanbul.

Cicioğlu , İ., Gökdemir , K., \& Erol, E. (1996). Pliometrik Antrenmanların 14-15 Yaş Grubu Basketbolcuların Dikey Siçrama Performansı ile Bazı Fiziksel ve Fizyolojik Paremetreleri Üzerine Etkisi. Hacettepe Üniveristesi Spor Bilimleri Dergisi, 7(1), 11 23.

Çelik, A., Günay, E., \& Aksu, F. (2013). 7-9 yaş grubu ilköğretim öğrencilerinin fiziksel ve motorik özelliklerinin değerlendirilmesi. Dokuz Eylül Üniversitesi Tip Fakültesi Dergisi, 27(1), 7-13.

Davis, R., Phillips , R., Roscoe , J., \& Roscoe, D. (2000). Physical Education and Study of Sport (4 edition b.). Mosby.

Diker, G., \& Müniroğlu, S. (2016). 8-14 Yaş Grubu Futbolcuların Seçilmiş Fiziksel Özelliklerinin Yaş Gruplarına Göre İncelenmesi. Ankara Üniversitesi Spor Bilimleri Fakültesi, 14(1), 45-52. DOI: 10.1501/Sporm_0000000283.

Gökhan, İ., Aktaş, Y., \& Aysan, H. A. (2015). Amatör Futbolcuların Bacak Kuvveti ile Sürat Değerleri Arasındaki İlişkinin İncelenmesi. International Journal of Science Culture and Sport (IntJSCS),, 4, 47-54. DOI: 10.14486/IJSCS356.

Göral,, , K., \& Göral, Ş. (2015). Kadın Futbolcularda Sprint Sürati, Dikey Siçrama ve Kuvvet Parametreleri Arasındaki İlişkilerin İncelenmesi. MANAS Sosyal Araştırmalar Dergisi, 4(3), 116-123.

Günay, M., \& Yüce, A. İ. (2008). Futbol antrenmanının bilimsel temelleri. Ankara: Gazi Kitap Evi. 
Hoffman, J. (2006). Norms for Fitness, Performance, and Health. Human Kinetics.

Korkmaz, N., Özduran , K., \& İlhan, A. (2003). Bursa ve Çevresinde 18-24 Yaşları Arasında Spor Yapan Gençlerin Sosyal Uyum Düzeylerinin İncelenmesi. Beden Eğitimi ve Spor Bilimleri Dergisi, 5(3), 17-25.

Milli Eğitim Bakanlığı. (2009, 06 16). Güzel Sanatlar ve Spor Liseleri Yönetmeliği. 2017 tarihinde http://www.resmigazete.gov.tr/eskiler/2009/06/20090616-7.htm adresinden alınd1

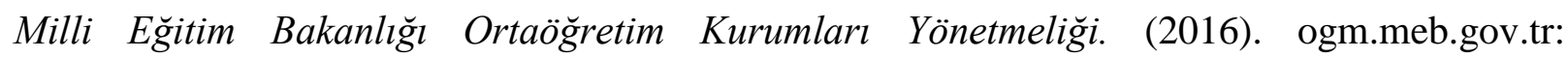
https://ogm.meb.gov.tr/meb_iys_dosyalar/2016_11/03111224_ooky.pdf adresinden alind1

Muratlı, S. (2007). Antrenman Bilimi Yaklaşımıyla Çocuk ve Spor. Ankara: Nobel Yayın Dağıtım.

Mücevher, M. H., Demirgil, Z., \& Erdem, R. (2015). Sportif aktivitelerin akademik başarı üzerindeki etkisi sdü iibf öğrencileri üzerine bir araştırma. V. Türkiye Lisansüstü Çalışmaları Kongresi, Bildiri kitabı I,, 119-132. DOI: 10.12658/TLCK.5.1.B008 .

Özsu, S. (2011). 12-14 Yaşlarında Yarışmacı Artistik Cimnastikçilerin Bazı Fiziksel Performans Parametrelerinin İncelenmesi. Selçuk Üniversitesi Beden Eğitimi ve Spor Bilim Dergisi, 13(3), 398-402.

Sevim, Y. (1997). Antrenman Bilgisi. Ankara: Tutibay Ltd. Şti.

Taşkın, C., Karakoç, Ö., Nacaroğlu, E., \& Budak, C. (2015). Futbolcu Çocuklarda Seçilmiş Motorik Özellikler Arasındaki İlişkinin İncelenmesi . Spor ve Performans Araştırmaları Dergisi, 6(2), 107-107. doi:10.17155/spd.74072.

Tiryaki, Ş., Erdil, G., Acar, M., \& Emlel, Y. (1991). Sporcu ve Sporcu Olmayan Gençlerin Kişilik Özellikleri. Spor Hekimliği Dergisi, 26, 19-23.

Tosun, A., Demir, B., Uçkun, G., \& Konak, O. (2015). Spor aktivitelerinin üniversite ögrencilerinin başart ve motivasyonu ile ilişkisi. 11. 10., 2016 tarihinde http://akademikpersonel.kocaeli.edu.tr/aykut.tosun/bildiri/aykut.tosun02.10.2015_15.40 .40bildiri.pdf adresinden alındı 